\title{
A PROPÓSITO DEL VOSEO: SU HISTORIA, SU MORFOLOGÍA Y SU SITUACIÓN EN COSTA RICA
}

\author{
Lillyam Rojas Blanco
}

Recibido 01-VI-2003 • Aceptado 10-VI-2003

\begin{abstract}
Resumen: La enseñanza y aprendizaje de la lengua materna, dentro de un contexto social, involucra, también, el entorno cultural. En este marco, se pretende, en concreto, un aporte a la capacitación de los docentes y las docentes en lo relativo al estudio diacrónico y sincrónico de la lengua española, en específico, a las formas de tratamiento de segunda persona singular, enfatizando en el paradigma de conjugación del voseo; se persigue tomar conciencia de que hay que valorar el dialecto propio, como medio de identidad socio-cultural, y en el hecho de que el empleo de vos no implica para nada una corrupción de la lengua y que no es un fenómeno circunscrito a Costa Rica, sino que es general a la América hispanohablante.
\end{abstract}

Palabras clave: Capacitación, Dialectología Lingüística, Diacronía, Sincronía, Voseo, Tuteo, Ustedeo.

\section{Justificación}

La enseñanza y aprendizaje del español dentro de un contexto social conlleva, ineludiblemente, otro elemento estrechamente relacionado con el lenguaje: el entorno cultural en el que se desarrolla. De tal modo, el estudio de la cultura le permite al docente de español impartir su materia en ese marco cultural y social. En cuanto al estudiante, le permite aprender y apreciar, mediante el lenguaje, los valores culturales, las tradiciones, las costumbres de su pueblo; también, puede reflexionar y tomar conciencia de que hay que valorar el dialecto propio, la manera particular de hablar, por cuanto abandonarlo es perder su identidad socio-cultural: perder la identidad lingüística implica perder la cultura.

Se trata, pues, de observar el dialecto propio como uno entre tantos; se trata de mantener y apreciar el dialecto vernáculo, paralelamente a propiciar una apertura hacia el aprendizaje del dialecto estándar y que pueda el discente manejar ambos, acorde con las diversas situaciones sociales.

En este marco, cuando el alumno estudia el paradigma verbal y pronominal, debe aprender a conjugar verbos con la forma tú, por cuanto ha de enfrentarse a ella en una variedad de contextos que van desde la televisión hasta la literatura; asimismo, es primordial que aprenda el uso adecuado de 
los pronombres usted y vos: sus correspondientes conjugaciones verbales y contexto pragmático (situaciones apropiadas para su uso o no).

Es nuestra intención, entonces, a través de una sencilla revisión diacrónica y sincrónica de las formas de tratamiento -en especial del voseo- contribuir a la formación idiomática adecuada, como medio para coadyuvar al reconocimiento del origen y evolución del idioma español, mejorar el desempeño personal, social y la identidad cultural al favorecer el respeto por la diversidad lingüística, estilística e histórica de la lengua española, así como aprovechar el instrumento de la lengua para la práctica de valores idiosincráticos costarricenses; también, favorecer la tolerancia, la seguridad lingüística entre los estudiantes al estudiar los diferentes tipos de discurso y propiciar la producción de textos orales y escritos con un empleo más adecuado de usted, tú y vos.

\section{Esbozo histórico}

Diversos investigadores coinciden en la complejidad que revisten no solo la génesis y el uso del pronombre vos en siglos anteriores al XX, sino también las diferentes posibilidades de realización de este pronombre en la América hispano-hablante actual (Lapesa, 1980; Resnick, 1980; Lipski, 1996; Rojas, 1992, 1998; etc.). Hablar de la génesis del voseo implica, obligatoriamente, referirse a la del pronombre tú, usted y al desuso en que cayó vosotros en América.

El vos es un arcaísmo hispánico que se consolidó y evolucionó al margen del español peninsular: un reajuste del sistema de tratamiento, originado por diversas causas. En fin, en el Nuevo Mundo, el paradigma del tuteo se fundió con el del vos medieval, de donde surgió el voseo americano. El empleo de vos en lugar de tú es rasgo peculiar de Hispanoamérica, que usan aproximadamente dos tercios de la población; los factores determinantes de esta forma de tratamiento giran en torno a dos ejes: el histórico y el social, tal y como se mencionará a continuación.

Así como los pronombres personales singulares go y tū produjeron las formas singulares yo y tú, en español, los pronombres plurales nōs y vōs se empleaban con valor tanto singular como plural, aun en el latín clásico. En cuanto a vōs, que originariamente había sido plural de tū, se empleaba en latín vulgar como pronombre singular de respeto; y con este uso lo encontramos tempranamente en el español antiguo (Resnick:1980, 89).

En el Cantar de Mio Cid, ya está presente esta alternancia vos-tú (en las formas pronominales y verbales): el pronombre vos aparecía usado como forma respetuosa de tratamiento directo entre nobles y entre cónyuges, mientras que tú servía para dirigirse a personas consideradas inferiores, $\mathrm{y}$ en las oraciones (Rojas, 1992:149; Resnick 1980:90). Este fenómeno parece indicar ya su probable alternancia en el habla.

Existían, pues, muchos casos de vacilación al seleccionar los pronombres y las correspondientes formas verbales, especialmente en los siglos XV y XVI. De tal modo, en el s. XV, vos -a pesar de estar ubicado gramaticalmente como segunda persona plural-solía asumir un papel formal de segunda persona singular de respeto, tanto en la época del descubrimiento de América como en los primeros años del s. XVI. En el cuadro № 1 pueden apreciarse, sucintamente, los usos principales de las formas de tratamiento a través de varios siglos.

Por su parte, tú se empleaba en el trato informal entre iguales, cuando había máxima intimidad, o bien, iba dirigido a interlocutores de una capa sociocultural inferior. Existía la preocupación, entre los españoles principales, de delimitar claramente la distancia social que los separaba de quienes pertenecían a un nivel social inferior. Esta función, en el plano lingüístico de las 
formas de tratamiento, le correspondió hasta el siglo XV al pronombre vos. De acuerdo con Resnick (1980: 90):

"En los siglos XVI y XVII, vos llegó a dominar como tratamiento para los familiares y los inferiores en las zonas rurales, y entre los soldados. Fue la forma traída por los Conquistadores a gran parte del Nuevo Mundo. Al dirigir la palabra a los indios, los trataban de vos, por considerarlos inferiores".

La situación descrita se mantuvo más o menos estable durante algún tiempo. Sin embargo, “...la aparición de la fórmula vuestra merced hacia fines del mismo siglo XV [...] provocaría el paulatino desplazamiento del vos de su lugar original" (Rojas, 1992:145).
En el s. XVII, se presenta abuso y desgaste fonético - por motivos sociales- de vuestra merced, la cual resultó, tras varios pasos intermedios, en la forma vuasted > usted; con la pérdida de la v inicial, obtenemos, pues, el pronombre personal moderno usted. Por este motivo, usted concuerda con el verbo en tercera persona singular. El plural de vuestra merced era vuestras mercedes, que después resultaría en ustedes, plural analógico sobre la base de usted.

Reiteramos: Ese desgaste y extensión de vuestra merced presiona y ocupa usos propios de vos. Así pues, "tú recobró terreno a costa de vos en el coloquio familiar, hasta eliminarlo durante el siglo XVII y quizá parte del XVIII" (Lapesa, 1980:578).

\section{Cuadro № 1}

Usos principales de vos, tú, vuestra merced, usted, ustedes, vosotros

\begin{tabular}{|c|c|c|c|c|c|}
\hline \multirow[t]{2}{*}{ Siglos } & \multirow[t]{2}{*}{ XII-XIV } & \multirow[t]{2}{*}{ XV-XVI } & \multirow[t]{2}{*}{ XVI-XVII } & \multicolumn{2}{|c|}{ XVIII-XX } \\
\hline & & & & España & América \\
\hline Vos & Respeto. & $\begin{array}{l}\mathrm{C} \\
\mathrm{o} \\
\mathrm{n} \\
\mathrm{f}\end{array}$ & $\begin{array}{l}\text { Principalmente rural y rús- } \\
\text { tico, familiaridad y con in- } \\
\text { feriores, y entre soldados. }\end{array}$ & $\begin{array}{l}\text { Se estigmatizó y } \\
\text { cayó en desuso. }\end{array}$ & $\begin{array}{l}\text { Familiaridad (algunas } \\
\text { regiones y clases } \\
\text { sociales). }\end{array}$ \\
\hline Tú & $\begin{array}{l}\text { Familiari- } \\
\text { dad y con } \\
\text { inferiores. }\end{array}$ & $\begin{array}{l}\mathrm{u} \\
\mathrm{s} \\
\mathrm{i} \\
\mathrm{o} \\
\mathrm{n}\end{array}$ & $\begin{array}{l}\text { Principalmente urbano y de } \\
\text { las clases altas, familiaridad } \\
\text { y con inferiores. Solidaridad } \\
\text { reemplaza a vos en España, } \\
\text { pero no en América. }\end{array}$ & Familiaridad. & $\begin{array}{l}\text { Familiaridad. } \\
\text { (algunas regiones y } \\
\text { clases sociales). }\end{array}$ \\
\hline Vuestra & $\ldots$ & Respeto & $\ldots$ & & \\
\hline Merced & & $\begin{array}{l}\text { Distancia } \\
\text { Surge a } \\
\text { fines del } \\
\text { XV. }\end{array}$ & $\begin{array}{l}\text { Por desgaste fonológico } \\
\text { resulta en usted. }\end{array}$ & $\cdots$ & $\cdots$ \\
\hline Usted & $\ldots$ & $\ldots$ & Respeto. & Cortesía, respeto. & $\begin{array}{l}\text { General a América. } \\
\text { Solidaridad/distancia } \\
\text { afectiva; neutraliza- } \\
\text { ción diafásica. }\end{array}$ \\
\hline Ustedes & $\ldots$ & $\ldots$ & Surge como plural analógico. & & $\begin{array}{l}\text { Desplaza a vosotros } \\
\text { en América. }\end{array}$ \\
\hline Vosotros & $\begin{array}{l}\text {... Alternaban } \\
\text { Vos latino y } \\
\text { la forma } \\
\text { enfática vos } \\
\text { alterus. }\end{array}$ & & & $\begin{array}{l}\text { En España, } \\
\text { excepto el } \\
\text { Occidente: } \\
\text { Andalucía y } \\
\text { Canarias. }\end{array}$ & $\begin{array}{l}\text { No se emplea; solo en } \\
\text { lenguaje bíblico, } \\
\text { afectado o juramentos. }\end{array}$ \\
\hline
\end{tabular}


En el siglo XVI, “...la forma vos decae socialmente en casi toda España y parte de América, para pasar a ocupar un espacio plebeyo sobre el mismo plano en que se desempeñaba el tú para el trato informal [...], el tú se habría empleado para dirigirse a los más jóvenes y a los adultos a quienes se les expresaba cariño" (Rojas, 1992:146). Como consecuencia, en España, a partir del s. XVIII, vos se estigmatizó y cayó en desuso: se generalizó tú para el trato familiar, y usted para el de cortesía. En cuanto a la América hispano-hablante, el tuteo predominará en parte de América; pero el voseo, durante la conquista de este continente, ya se había arraigado en una amplia extensión territorial. Tales hechos, en opinión de diversos estudiosos, no se evidencian cabalmente antes del siglo XVIII.

Finalmente, la forma vosotros (vos + elemento enfático -otros; Cano, 1988:214) aparece ya en algún ejemplo en el S. XIII, consecuencia de la confusión ocasionada por el uso indiscriminado de vos sin atender al número; en los siglos XIV y XV, ya se observa claro el valor enfático y contrastivo. En términos de Lathrop (1992:154155): "Nos y vos tenían formas paralelas enfáticas en latín vulgar, nos alteros y vos alteros, y fueron finalmente estas formas las que se impusieron en español frente a nos y a vos, a finales de la Edad Media”.

\section{Distribución geográfica}

Para siglos anteriores al XX, es tarea difícil obtener datos absolutamente precisos acerca de la situación del tratamiento de confianza, en las distintas regiones de América, debido a que, por estar en manos de amanuenses, quienes tenían el deber de seguir las reglas estilísticas de la época, por los diversos orígenes de los declarantes, autores, etc. y, dada la naturaleza misma de los documentos, no podemos conocer con exactitud el uso informal del habla. En opinión de Elena Rojas (1992:151-152): “...en las regiones en que se produjo la sustitución del pronombre vos por el tú en el trato simétrico y asimétrico entre familiares, vos compitió intensamente con vuestra merced, hasta que usted tomó un lugar firme por mucho tiempo, en el uso asimétrico de jóvenes a padres, tíos, abuelos, personas mayores en general".

Si se toma como criterio fundamental el hecho de que México y Perú, por albergar las más desarrolladas culturas indígenas, por ser centros importantes de dominación española durante la colonia, por el contacto constante que mantenían con la Península, se constituyeran en reproductores y focos de difusión del legado cultural y, por tanto, también el hecho de que haya contribuido la rígida división de clases, así como la imitación de modas culturales y lingüísticas, todo ello influiría en una mayor difusión y predominio del tuteo. Por otro lado, en regiones más alejadas y con menor contacto con España y menor influencia de esta, existía mayor probabilidad de conservar el voseo que les llegó desde la metrópoli en los primeros tiempos de la colonización, podía presentarse conflicto entre el voseo y el tuteo, que se refleja en su paradigma pronominal y verbal.

Exceptuando a las Antillas, todos los países de América presentan algún tipo de voseo, por lo menos, en alguna de sus regiones (véase el cuadro № 2); tal como comenta Lapesa (1980:578):

"Las cortes virreinales adoptaron y difundieron estos cambios en las formas de trato social, que hoy son las únicas vigentes en casi todo Méjico, en la mayor parte del Perú y Bolivia y en las Antillas, donde influyó la acción cultural de la Universidad de Santo Domingo, así como la mayor duración de la dependencia política respecto a España. Pero en Argentina, Uruguay, Paraguay, América Central y el estado mejicano de Chiapas domina el vos en la conversación familiar con intensa y espontánea vitalidad; en Panamá, Colombia, Venezuela, Ecuador, Chile, zonas norteñas y Sur del Perú, así como en el Sur de Bolivia, alternan tú y vos".

La preocupación peninsular por fijar el idioma, reflejada en la Real Academia de la Lengua, desde los albores del siglo 
XVIII, puede haber influido directamente, desde los distintos centros de enseñanza universitaria, sobre las sociedades americanas más desarrolladas culturalmente o con mayor contacto con la metrópoli, de ahí que México, Las Antillas y Perú, en especial, parezcan haberse encaminado hacia la definición por el tuteo, luego de sus vicisitudes sufridas conjuntamente con otras regiones hispanoamericanas hasta el S. XVIII (Vid. Elena Rojas, 1992:153).

Por otra parte, el tuteo es de uso exclusivo solamente en tres países de América: la República Dominicana, Puerto Rico y Cuba, los cuales mantuvieron más contacto con la España tuteante después del siglo XVI. Sin embargo, apunta López Morales, en Estudio sobre el español de Cuba (1971, 136-142, Cit. en Lapesa 1980:578): "En Cuba existió voseo en Camagüey y Bayamo, según atestigua Pichardo en 1836; pero en 1875 añade que estaba reduciéndose a 'un corto número del vulgo'. Exploraciones recientes no han encontrado restos ya".
Miguel Angel Quesada (2000:86) ubica el tuteo como usual y general en el Suroeste de los Estados Unidos, México (excepto, en cierta medida, en Chiapas y Tabasco), las Antillas, Panamá, Colombia (costa atlántica), Venezuela (salvo los estados de Zulia y Mérida), Ecuador (costa), Perú, Bolivia (clase alta) y Chile.

En cuanto al ustedeo, cabe apuntar, en palabras del investigador costarricense Miguel Ángel Quesada (2000:89-90).

"Al margen del uso de vos o tú como tratamiento en el plano de la solidaridad, se asoma usted con el mismo valor en regiones como Honduras, Costa Rica, $\mathrm{Pa}$ namá (zona occidental, donde convive con vos), Colombia, Venezuela, Bolivia (Oriente), Argentina (noroeste) y Chile. En las regiones donde se emplea hay una neutralización pronominal, de manera que usted vale tanto para el plano de la solidaridad como del distanciamiento, y se utiliza para todo tipo de personas y en cualquier situación”.

En lo que corresponde al plural, el empleo de ustedes es general a toda la América hispanohablante; así como al mediodía español (Canarias y Andalucía)

\section{Cuadro № 2}

Distribución geográfica actual hispanoamericana de vos, tú, usted, ustedes, vosotros

Siglos XX-XXI

Vos

Tú

Honduras, Costa Rica, Panamá (occidental, convive con vos), Colombia, Venezuela, Bolivia (oriente), Argentina (N.O.) y Chile.

Ustedes General a Hispanoamérica.

Desplaza a vosotros en América.

Se presenta neutralización.

Vosotros No se emplea en América.
Domina en la conversación familiar.

Familiaridad

(algunas regiones y clases sociales).

En las Antillas, de uso exclusivo.

Vale para solidaridad, distancia o poder, cualquier persona, cualquier situación.

Solo en lenguaje bíblico, afectado o juramentos. 
(Cfr. Alarcos, 1995:77); se utiliza para señalar tanto distancia y poder, como solidaridad entre los interlocutores. Desplaza a vosotros/as que ya no se emplea en América, excepto en el lenguaje bíblico, en el lenguaje afectado y en los juramentos (i.e., al graduar nuevos profesionales o al comenzar a ejercer determinados cargos).

Muy probablemente, el avance que tuvo el voseo en América ocasionó el desplazamiento de la forma de plural vosotros del paradigma correspondiente, puesto que en muchas ocasiones se usaba vos por vosotros, y ello habría causado confusiones. Así que, en su lugar, arraigó ustedes, el cual en nuestros días sirve en toda la América hispano-hablante para expresar la pluralidad de tú, vos y usted.

\section{El voseo en Costa Rica}

En lo relativo a por qué arraigó tanto en Costa Rica el voseo, se esgrimen varias razones históricas entre las que cabe mencionar que Costa Rica, por su ubicación geográfica y por su escasa densidad poblacional, permaneció muy aislada del resto de las provincias españolas y con muy poco contacto cultural con estas; en el mismo territorio costarricense los habitantes vivían muy dispersos. Todo esto pudo haber influido en que se mantuvieran y cultivaran características culturales y lingüísticas, como el voseo, que en otras partes iban cambiando o desapareciendo. "Si, por último, se considera que el voseo tiende a igualar la condición de quienes lo usan, su existencia y difusión son muy explicables en una sociedad donde -si bien ha habido diferencias-, la gente ha estado demasiado imbuida en la idea de que todos son iguales" (Carlos Vargas, 1974:10).

Varios autores han abordado, de un modo u otro, el voseo en nuestro país; podemos citar los siguientes: Rafael Lapesa
(1980), John Lipski (1996), José Cuervo (1947), Carlos Gagini (1929), Arturo Agüero (1973), Miguel Angel Quesada (1990, 2000), Carlos Vargas (1974), Yamilet Solano (1986), Víctor Sánchez (1996).

Agüero (1973:96) menciona el empleo de vos en Costa Rica, aunque desde una perspectiva academicista al exponerlo como "mezcolanza de usar el acusativo y dativo te en lugar de os y el error de correspondencia de usar con vos el posesivo de segunda persona singular tu, y no la segunda de vuestro". Añade que, en Costa Rica, en aquel momento, predominaba aplastantemente el empleo de vos en detrimento de tú: “...solo se les tolera a los extranjeros, pues al nacional que lo use se lo considera pedante y afectado. No hay aquí tal lucha con el tuteo" (1973:99).

Los libros de texto y las gramáticas escritas en nuestro territorio o pasan por alto el empleo de vos, o no le conceden la debida importancia.

Entre los estudios o menciones ya con orientación lingüística más definida, cabe destacar la labor del investigador Víctor Manuel Sánchez (1996:165 y ss.), quien presenta tanto el modelo pronominal académico como el costarricense y procura motivar a los estudiantes hacia la toma de conciencia del empleo de usted, ustedes y vos en el país. En el apartado 4.2. ampliaremos un poco con respecto a los pronombres.

Carlos Vargas efectúa, en 1974, un estudio del voseo en nuestro país. Ofrece una serie de consideraciones históricas, sociales y lingüísticas sobre el surgimiento y uso del voseo; posteriormente, lleva a cabo un análisis descriptivo con base en encuestas aplicadas a 68 personas, mayores de edad, estudiantes universitarios.

Nos parece importante destacar algunas de las respuestas que encontró en relación con el uso de los diferentes pronombres. Para la forma usted, los informantes expresaban su uso con personas que no conocen, entre padres e hijos (tanto 
para mostrar afecto como para regañar), entre matrimonios de mucha confianza, con la pareja; también, para manifestar respeto, reproche, resentimiento, al sentirse enojados e, incluso, para dar consejo a alguien que se trata usualmente de vos. Por su parte, vos se marcó como pronombre para indicar confianza, familiaridad, amistad; se usa de igual a igual, con quienes comparten el mismo nivel social y cultural, incluso con empleados y personas menores de edad o menores que el hablante, para infundir confianza y que no se apenen. Finalmente, en cuanto al tú, se lo calificó como indicador de pedantería en el usuario, de una persona poco amistosa, que inclusive puede querer llamar la atención o tiene problemas de personalidad; en fin, también se percibió como afeminado o femenino, y hasta romántico.

Yamilet Solano lleva a cabo, en 1986, un estudio titulado "Formas de tratamiento diádico en los niños escolares de una comunidad de Costa Rica”. En su trabajo, se basa en una comunidad lingüística compuesta por el personal de cuatro escuelas urbanas de San Ramón de Alajuela; aplica tres métodos: observación (estructurada y no estructurada), entrevista formal y métodos cuantitativos informáticos. Los niños escolares, en dicha comunidad, solo saben emplear usted en todas las situaciones; los directores también utilizan mucho el ustedeo; los conserjes lo utilizan entre compañeros de la misma edad o si el receptor es extrovertido y jovial. Los maestros son los más innovadores, tienden a usar más el vos y están dispuestos a recibirlo. Predomina, en general, el empleo de usted. Como factores condicionantes encuentra la edad y la autoridad. En cuanto a las actitudes, encontraron que la forma tú está evaluada negativamente, la ubican como afeminada, en el código oral; no obstante, en el escrito, se carga de valores positivos: marcador de prestigio de lengua culta. Considera Solano que la razón más importante para no escribir en vos es la inseguridad, dado que la conjugación no ha sido formalmente aprendida en el voseo; el hablante no sabe escribir la forma verbal adecuada. La forma usted, agrega, es apropiada para cualquier situación en virtud de que no es despectiva y, además, expresa, a un tiempo, cariño y respeto, por ello se utiliza entre cónyuges y con los niños.

Para Cargos Vargas (1974) y Yamilet Solano (1986), es necesario desterrar la idea del voseo costarricense como forma corrupta de vosotros, de tú y de mezcolanza de formas; así también, Solano plantea la necesidad de incluir, en la escritura, en la educación formal, la forma vos completa (paradigma verbal y pronominal; contextos de uso), como medio de terminar con la inseguridad que tanto adultos como niños experimentan a la hora de escribir y de hablar con esta variante.

\section{Morfología del voseo}

En Costa Rica encontramos voseo pronominal-verbal. En este, el pronombre vos está acompañado de una forma verbal generalmente monoptongada (-ás, -és, -ís), derivada de una de las diptongadas (-áis, -éis) -que aún se usan con el pronombre de segunda persona plural vosotros en España, también en algunas partes del territorio americano-. También encontramos voseo verbal, el cual se manifiesta gracias a la posibilidad que brinda el español de indicar la persona del sujeto mediante sus desinencias de persona, sin necesidad de que lo consigne el sujeto; las correspondientes al voseo son las formas monoptongadas citadas.

\subsection{En los verbos}

A continuación, vamos a presentar la conjugación verbal correspondiente al 
empleo del pronombre vos. En cada tiempo verbal, ofrecemos un ejemplo de cada grupo de conjugación (ar, er, ir) regular para cada pronombre, tú y vos, respectivamente, con el objeto de facilitar la comparación; decidimos efectuar tal contraste, en vista de la generalizada "confusión" e inseguridad lingüística evidentes tanto en docentes del área de español, profesionales de otras áreas, así como estudiantes de secundaria y de universidad. También, en cuanto a los verbos irregulares, siguiendo a P.H. Mathews (1980), y a Garita (2002), así como a la Gramática de la Academia (1991), hablaremos de los procesos esquematizados en el Cuadro № 3), los cuales mencionaremos y ejemplificaremos en los distintos tiempos verbales, según sea pertinente en cada caso y para los fines del presente trabajo.

\subsubsection{Indicativo}

\section{Presente}

En la primera y segunda conjugaciones, la diferencia entre el voseo y el tuteo parece limitarse a la posición del acento: en los ejemplos correspondientes a vos, el acento del verbo es oxítono (agudo), y recae en la desinencia, propio de la forma vosotros, según puede apreciarse en el cuadro № 4 . En contraste, en la tercera conjugación, el verbo recibes sufre el cambio de vocal temática i $>$ e, propio de esta conjugación y de las formas fuertes de singular y plural (posición tónica; Alcina, 1975:769); mientras que recibís permanece idéntico a la segunda persona plural (vosotros) y con vocal temática -i por corresponder a la forma débil. Es necesario indicar que la terminación -s para tú se ha conservado, desde el latín, sin cambios.

Cuadro № 3

Esquema de las principales irregularidades verbales

\begin{tabular}{|c|c|c|c|}
\hline \multirow{4}{*}{ Reemplazamiento } & \multirow[t]{2}{*}{ Vocálico } & Debilitamiento & Diptongación \\
\hline & & $\mathrm{E} / \mathrm{i}, \mathrm{o} / \mathrm{u}$ & o/ue, e/ie, i/ie, u/ue \\
\hline & Consonántico & \multicolumn{2}{|l|}{$\mathrm{C} / \mathrm{g}, \mathrm{b} / \mathrm{y}$} \\
\hline & Mixto & \multicolumn{2}{|c|}{ Ec/ig, ab/ep, ab/up, ec/ij } \\
\hline \multirow[t]{2}{*}{ Adición } & Consonántica & \multicolumn{2}{|l|}{$\mathrm{Z}, \mathrm{j}, \mathrm{g}, \mathrm{y}$} \\
\hline & Mixta & \multicolumn{2}{|l|}{$\mathrm{Ig}$} \\
\hline \multirow[t]{2}{*}{ Sustracción } & \multicolumn{3}{|c|}{ Supresión de vocal temática } \\
\hline & \multicolumn{3}{|c|}{ Supresión de vocal temática y adición de "d" } \\
\hline
\end{tabular}

Cuadro № 4

Conjugación regular en los tiempos simples de indicativo

\begin{tabular}{|c|c|c|c|c|c|c|}
\hline \multicolumn{4}{|c|}{ Presente } & \multicolumn{3}{|c|}{ Condicional (potencial) } \\
\hline Tú & Cantas & Corres & Recibes & Cantarás & Correrás & Recibirás \\
\hline Vos & Cantás & Corrés & Recibís & Cantarás & Correrás & Recibirás \\
\hline \multicolumn{4}{|c|}{ Pretérito imperfecto } & \multicolumn{3}{|c|}{ Futuro } \\
\hline Tú & Cantabas & Corrías & Recibías & Cantarías & Correrías & Recibirías \\
\hline Vos & Cantabas & Corrías & Recibías & Cantarías & Correrías & Recibirías \\
\hline \multicolumn{4}{|c|}{ Pretérito perfecto simple } & & & \\
\hline Tú & Cantaste & Corriste & Recibiste & & & \\
\hline Vos & Cantaste & Corriste & Recibiste & & & \\
\hline
\end{tabular}


Cuadro № 5

Reemplazamiento vocálico y adición consonántica en presente

\begin{tabular}{|l|l|l|l|l|l|c|}
\hline Pron. & E/i & E/ie & I/ie & O/ue & U/ue & “y” \\
\hline Tú & Mides & Quieres & Requieres & Cuentas & Juegas & Construyes \\
\hline Vos & Medís & Querés & Requerís & Contás & Jugás & Construís \\
\hline Tú & Pides & Tienes & Inquieres & Muerdes & & Retribuyes \\
\hline Vos & Pedís & Tenés & Inquirís & Mordés & & Retribuís \\
\hline Tú & Sirves & Vienes & Adquieres & Duermes & & Huyes \\
\hdashline Vos & Servís & Venís & Adquirís & Dormís & & Huís \\
\hline
\end{tabular}

En el presente en general, en cuanto a irregularidades verbales, encontramos reemplazamiento vocálico y adición consonántica, tal como en los ejemplos del cuadro № 5 donde observamos las diferencias entre las formas verbales de tú y de vos.

Las formas del tuteo, debilitan en el primer caso (e>i) y diptongan en los ejemplos de las otras cuatro columnas, por ser formas fuertes, graves (o de acento paroxítono). En cuanto a las del voseo, son todas formas agudas regulares, conservan la vocal de la raíz (no debilitan ni diptongan la vocal radical) por constituir una forma débil y estar emparentadas más directamente con vosotros, como se observa más evidentemente en las formas de la tercera conjugación, las cuales conservan igualdad de forma respecto de vosotros (medís, pedís, servís, venís, adquirís, dormís, etc.).

Asimismo, apreciamos, en este tiempo verbal, en los ejemplos de la última columna, el fenómeno de adición consonántica de la "y" en las formas de la segunda persona tú, pero no en las formas del voseo, que están más estrechamente ligadas con vosotros y quedan con la misma expresión fonética.

En el Cuadro № 6, observamos la idéntica manifestación fonética en las formas correspondientes a los tres primeros verbos; en ciertos verbos, no se puede establecer con exactitud si se trata de una monoptongación del voseo o si, en realidad, es una forma del tuteo (Cfr. Elena Rojas, 1992:156). En cuanto a ser, la forma verbal sos procede claramente de sois, con pérdida de la i; y con eres, nos encontramos posiblemente con el único resto en español del antiguo futuro, pues la segunda persona singular futura de esse (ser) era eris > eres (Lathrop, 1992:63).

\section{Cuadro № 6}

Otras irregularidades en presente

\begin{tabular}{|c|c|c|c|c|}
\hline Pron. & IR & ESTAR & DAR & SER \\
\hline Tú & Vas & Estás & Das & Eres \\
\hdashline Vos & Vas & Estás & Das & Sos \\
\hline
\end{tabular}

Pretérito imperfecto

Encontramos, sin lugar a dudas, igualdad de formas entre el voseo y el tuteo (vid. Cuadro № 4). Las formas de conjugación de vos pueden surgir por analogía, pues esta se deja sentir en formas que desempeñan las mismas funciones, unas influyendo sobre otras. Dada esta igualdad verbal formal, ante una expresión como "Siempre cantabas", únicamente por el uso del pronombre sujeto (tú, vos) determinaremos si se trata de un hablante voseante o tuteante. La sola semejanza formal de dos voces basta frecuentemente para la confusión (García de Diego, 1951:142).

En este tiempo verbal, hallamos tres verbos irregulares: ibas, veías, eras $(<$ ir, 
ver, ser); destacamos aquí lo relativo a las formas de tú y vos, las cuales presentan identidad de forma $y$, por tanto, ameritan el empleo del pronombre sujeto para discriminar voseo - tuteo. La primera forma ibas, es irregular debido a que, a pesar de pertenecer a la tercera conjugación, retiene la $\mathbf{b}$ del morfema de pretérito imperfecto; la segunda, veías, lo es porque conserva la raíz ve (del antiguo español veer < vīd re). Por último, eras es irregular por cuanto, además de la pérdida de la raíz $\mathbf{s}$ (< ser), es la continuación del imperfecto irregular eram (del antiguo esse, 'ser, estar').

Pretérito perfecto simple (pret. indefinido)

En las tres conjugaciones, se presenta igualdad de formas entre vos y tú, por analogía; otra vez, será el uso del pronombre sujeto (tú, vos) el que indique si el hablante está voseando o tuteando (tal como podemos apreciar en el Cuadro № 4).

Para Elena Rojas (1992:156) no se confunden en realidad en el habla popular pues se emplean las formas con $-\mathrm{s}$ propias del voseo. En Costa Rica, en general, se observa el empleo de $-\mathbf{s}$ al final de la palabra en personas de menor educación formal y de extracción geográfica no citadina. Según expone Menéndez Pidal, es frecuente añadir en el habla vulgar una -s que tiende a unificar la desinencia con las desinencias generales (cambio por analogía), cuyo uso no es culto (1982:279-280); ya en el siglo XVIII hay ejemplos de esta práctica "vulgar", pues también dicen cogites 'cogiste' los judíos de Oriente salidos de España a principios de la Edad Moderna.

La terminación -sti > -ste no lleva la -s que caracteriza a la desinencia general; vino a añadírsele después. Según Menéndez Pidal (1982:280), en cuanto a -stis, -stes, hasta el s. XVIII sólo se decía amastes; pero se quiso uniformar esta desinencia con la general y se presentaron dos posibilidades: (a) proveerla de la dental de amássedes, etc., diciendo dístedes, tendencia que no arraigó; y (b) proveerla del diptongo -is, diciendo amasteis, forma que aparece ya en el paradigma de una gramática en 1555 y que es la empleada en la actualidad para vosotros. Estamos ante una analogía de sufijo (García de Diego, 1951:142), por cuanto “...un sufijo puede ser atraído por otro en razón de su mayor uso o a partir de una forma descollante"; la forma -is aparece en el presente de indicativo, así como en el pretérito imperfecto de indicativo, mencionados arriba.

En cuanto a los verbos irregulares, ejemplificamos, a continuación, reemplazamiento vocálico $(\mathrm{o} / \mathrm{u}, \mathrm{e} / \mathrm{i})$, consonántico (c/j) y mixto (ab/up, ec/ij), así como adición consonántica (j) (véase el cuadro № 7).

Encontramos aquí formas fonéticas idénticas en el tuteo y el voseo: con la misma terminación; pero, además, las formas correspondientes a vos sufren los mismos cambios fonológicos que las de tú (debilitamiento, reemplazo mixto ab/up, ec/ij, etc.). Por medio del empleo explícito del pronombre sujeto (vos, tú) se especificará si el hablante o la hablante está voseando o tuteando en una frase como, por ejemplo: “Qué me dijiste?”.

Cuadro № 7

Conjugación irregular en pretérito perfecto simple

\begin{tabular}{|c|c|c|c|c|c|c|}
\hline Pron. & O/u & E/i & C/j & Ab/up & Ec/ij & $\mathrm{J}$ \\
\hline Tú & Pudiste & Viniste & Tradujiste & Supiste & Dijiste & Trajiste \\
\hline Vos & Pudiste & Viniste & Tradujiste & Supiste & Dijiste & Trajiste \\
\hline Tú & & & Condujiste & Cupiste & Bendijiste & \\
\hline Vos & & & Condujiste & Cupiste & Bendijiste & \\
\hline
\end{tabular}


Cabe acotar que las formas correspondientes a vosotros también sufren tales irregularidades: pudisteis, vinisteis, supisteis, dijisteis, tradujisteis.

Futuro y potencial (condicional) simples

La tendencia más analítica del latín vulgar, llevó a la lengua a encontrar una construcción analítica con la que sustituir las formas complejas y ambiguas del futuro clásico; se trata de la construcción perifrástica de futuro: infinitivo + habere en presente de indicativo. El verbo habere presenta, en el latín vulgar, formas más cortas que en el clásico: por un lado, por analogía con otros verbos usuales cortos y, por otro, por su nueva función de auxiliar no acentuado (Cfr. Lathrop, 1995:62 y ss; Resnick, 1981:99 y ss). Observemos las formas verbales en el cuadro № 8 .

Podemos, pues, colegir que las formas correspondientes a vos perdieron, por analogía, la -i en el morfema de persona; motivo por el cual se homologan las formas del tuteo y del voseo, en estos dos tiempos, según se observa en el cuadro № 4 .

Por último, en Costa Rica se escucha el futuro en -ré, como en, i.e.: cantarés, comerés, vivirés; en coexistencia con las formas homologadas al tuteo ya citadas (Cfr. Lapesa, 1980:579-580). Son formas regulares que se diferencian de vosotros por la ausencia de la -i átona desinencial, a criterio de Carlos Vargas (1974:16). En su opinión, si estas formas no les parecen a muchos tan conocidas, es debido a que son personas con mayor contacto con la lengua escrita y, aunque no usen al hablar el tú, están muy familiarizadas con este pronombre y sus correspondientes formas verbales. Pero, en el habla, puede escucharse, en estilo informal, entre personas de menor educación y quizá de origen no capitalino, expresiones como: "Esperate y verés".

Por su parte, la evolución del condicional es paralela a la del futuro; esta construcción de infinitivo + habere iba incluso a dar origen a un tiempo condicional (desconocido en el latín clásico). Ahora, es el imperfecto de habere el que pasa a emplearse tras infinitivo. Y, también por analogía, surgen las formas del vos.

En cuanto a las formas verbales irregulares, ejemplificadas en el cuadro $\mathrm{N}^{\circ} 9$, se presenta el fenómeno denominado sustracción: en unos verbos se suprime la vocal temática; en otros, además de esto, se inserta una consonante suplementaria, con el fin de facilitar la pronunciación.

En estos dos tiempos romances (futuro y condicional), encontramos doce verbos irregulares: caber, haber, querer, poder y saber presentan sustracción; mientras que poner, salir, tener, valer y venir presentan, además de sustracción, inserción de la consonante suplementaria recién mencionada, tal como puede apreciarse en el cuadro № 9. Por otro lado, el futuro de

Cuadro № 8

Formas verbales de habere

\begin{tabular}{|c|c|c|c|}
\hline Latín clásico & Latín vulgar & Español & Ortografía moderna \\
\hline Hábeo & áio & Cantar he & Cantaré \\
Hábes & as & Cantar has & Cantarás \\
Hábet & at & Cantar ha & Cantará \\
Habēmus & (ab)emus & Cantar hemos & Cantaremos \\
Habētis & abétis & Cantar heis & Cantaréis \\
Hábent & ant & Cantar han & Cantarán \\
\hline
\end{tabular}


los otros dos verbos irregulares, hacer y decir, se forma sobre la base de las antiguas variantes de infinitivo (far y dir). De este modo, observamos identidad fonética entre el tú y el vos, tanto en los verbos regulares, como en los irregulares.

Tiempos compuestos

En todos los tiempos compuestos del indicativo, encontramos similitud de formas para el voseo y el tuteo; fenómeno debido a la analogía. Al igual que el futuro y el condicional, los tiempos compuestos son de formación vulgar, aunque continúan con tendencias ya existentes en latín. Va a ser el empleo de vos o tú como pronombres sujetos lo que permita determinar si el hablante prefiere ser voseante o no.

En cuanto al pretérito perfecto compuesto, habéis cantado (que pudo haber resultado en la forma habés cantado para el voseo) queda en el español actual como has, por analogía con has de la forma tú. En la forma habrías del condicional (potencial) futuro, encontramos sustracción de la vocal temática. En el futuro perfecto, las formas verbales para vos, por analogía, resultan con idéntica expresión lingüística a las del tú (ver el Cuadro № 10).

\subsubsection{Modo subjuntivo}

\section{Presente}

$\mathrm{Al}$ igual que en el presente de indicativo, en el de subjuntivo la diferencia entre el voseo y el tuteo parece limitarse a la posición del acento: en los ejemplos correspondientes a vos, el acento del verbo es oxítono (agudo), y recae en la desinencia, propio de la forma vosotros, según podemos observar en el Cuadro № 11 .

En el presente de subjuntivo, en cuanto a irregularidades verbales, encontramos: reemplazamiento vocálico, consonántico y mixto, adición consonántica y mixta. Dada la complejidad y variedad de formas, los ejemplos se ofrecen separados en los Cuadros № 12, 13, 14 y 15. Comparemos las formas del tú con las del vos.

\section{Cuadro № 9}

Conjugación irregular en futuro y condicional simples

\begin{tabular}{|l|l|l|l|l|l|c|c|}
\hline Pron. & Caber & Haber & Poder & Saber & Poner & Tener & Salir \\
\hline Tú & Cabrás & Habrás & Podrás & Sabrás & Pondrás & Tendrás & Saldrás \\
\hline Vos & Cabrás & Habrás & Podrás & Sabrás & Pondrás & Tendrás & Saldrás \\
\hline Tú & Cabrías & Habrías & Podrías & Sabrías & Pondrías & Tendrías & Saldrías \\
\hline Vos & Cabrías & Habrías & Podrías & Sabrías & Pondrías & Tendrías & Saldrías \\
\hline
\end{tabular}

Cuadro № 10

Tiempos compuestos de indicativo

\begin{tabular}{|c|c|c|c|c|c|c|}
\hline \multicolumn{4}{|c|}{ Pretérito perfecto compuesto } & \multicolumn{3}{c|}{ Condicional (potencial) perfecto } \\
\hline Tú & Has cantado & Has corrido & Has recibido & Habrías cantado & Habrías corrido & Habrías recibido \\
\hdashline Vos & Has cantado & Has corrido & Has recibido & Habrías cantado & Habrías corrido & Habrías recibido \\
\hline \multicolumn{3}{|c|}{ Pretérito pluscuamperfecto } & \multicolumn{3}{c|}{ Futuro perfecto } \\
\hline Tú & Habías cantado & Habías corrido & Habías recibido & Habrás cantado & Habrás corrido & Habrás recibido \\
\hline Vos & Habías cantado & Habías corrido & Habías recibido & Habrás cantado & Habrás corrido & Habrás recibido \\
\hline
\end{tabular}


Cuadro № 11

Tiempos simples y compuestos de subjuntivo

\begin{tabular}{|c|c|c|c|c|c|c|}
\hline \multicolumn{3}{|c|}{ Presente } & \multicolumn{3}{c|}{ Pretérito perfecto } \\
\hline Tú & Cantes & Corras & Recibas & Hayas cantado & Hayas corrido & Hayas recibido \\
\hline Vos & Cantés & Corrás & Recibás & Hayás cantado & Hayás corrido & Hayás recibido \\
\hline \multicolumn{3}{|c|}{ Pretérito imperfecto } & \multicolumn{3}{c|}{ Pretérito pluscuamperfecto } \\
\hline Tú & Cantaras & Corrieras & Recibieras & Hubieras cantado & Hubieras corrido & Hubieras recibido \\
\hline Vos & Cantaras & Corrieras & Recibieras & Hubieras cantado & Hubieras corrido & Hubieras recibido \\
\hline
\end{tabular}

$\mathrm{Al}$ observar los procesos de reemplazamiento vocálico (debilitamiento y diptongación) en el Cuadro № 12 , la primera diferencia que salta a la vista consiste en que las formas verbales de tú y de vos se distinguen en función del acento: oxítono en el vos. Por un lado, en el tuteo, las formas debilitan en el primer caso (e>i), y diptongan en los ejemplos de las otras cuatro columnas, al igual que las restantes formas fuertes (o de acento en el radical). Por otro lado, se observa debilitamiento e>i en varias formas verbales: en midás, pidás, sirvás, sintás, mintás y de o> u en durmás. Estos últimos cambios se deben a que los verbos medir, pedir, servir, sentir, mentir y dormir son irregulares con debilitamiento vocálico en las terceras personas del pretérito perfecto simple; por ello, también resultan irregulares las formas de presente Subj. de vosotros: midáis, pidáis, etc.

En el Cuadro № 13, apreciamos que las formas verbales de ambos pronombres se distinguen en función de la posición del acento. Tanto las formas correspondientes a tú como las de vos (y las restantes de estos verbos en este presente) evidencian reemplazamiento. En general, cuando un verbo es irregular en la primera persona del indicativo, también lo será en el presente de subjuntivo. Para los ejemplos anteriores encontramos los presentes de indicativo: hago, rehago, hay, digo, quepo, sé.

Cuadro № 12

Reemplazamiento vocálico en el presente de subjuntivo

\begin{tabular}{|l|l|l|l|l|l|}
\hline Pron. & E/i & E/ie & I/ie & O/ue & U/ue \\
\hline Tú & Midas & Sientas & Adquieras & Cuentes & Juegues \\
\hline Vos & Midás & Sintás & Adquirás & Contés & Jugés \\
\hline Tú & Pidas & Quieras & Inquieras & Muerdas & \\
\hline Vos & Pidás & Querás & Inquirás & Mordás & \\
\hline Tú & Sirvas & Mientas & Requieras & Duermas & \\
\hdashline Vos & Sirvás & Mintás & Requirás & Durmás & \\
\hline
\end{tabular}

Cuadro № 13

Reemplazamiento consonántico y mixto en el presente de subjuntivo

\begin{tabular}{|c|l|l|c|c|}
\hline Pron. & C/g & B/y & Ec/ig & Ab/ep \\
\hline Tú & Hagas & Hayas & Digas & Quepas \\
\hline Vos & Hagás & Hayás & Digás & Quepás \\
\hline Tú & Rehagas & & & Sepas \\
\hline Vos & Rehagás & & Sepás \\
\hline
\end{tabular}


También se evidencia, en este tiempo verbal, el fenómeno de adición consonántica, tanto en las formas de tú como en las de vos. Aquí, discriminamos las formas del tuteo y las del voseo en función del acento agudo de estas últimas (ver Cuadro $\mathrm{N}^{\circ}$ 14).

En cuanto a la información contenida en el Cuadro № 15, con excepción de des y estés, las formas del tuteo y del voseo se distinguen gracias a la ubicación del acento agudo para este último. Observamos la idéntica manifestación fonética en las formas correspondientes a los cuatro verbos; aquí vale también lo ya apuntado para el presente de indicativo: no podemos establecer con exactitud si, en el caso de vos, es una monoptongación a partir de vosotros o si, en realidad, es una forma del tuteo.

\section{Pretérito imperfecto}

Se presenta similitud entre las formas verbales de ambos pronombres; por tanto, solo por medio del pronombre sujeto podremos distinguir una persona voseante de una tuteante, tal como podemos apreciar en el Cuadro № 11 .

Este tiempo presenta diversas irregularidades; partimos del hecho de que, si un verbo presenta irregularidad en el pretérito indefinido de indicativo, también la presentará en este pretérito de subjuntivo. Nos basamos en el imperfecto en -ra por cuanto es el de empleo general en Costa Rica. Observamos, entre los verbos irregulares, los siguientes fenómenos: reemplazamiento vocálico $(\mathrm{o} / \mathrm{u}, \mathrm{e} / \mathrm{i})$, consonántico $(\mathrm{c} / \mathrm{j})$ y mixto (ab/up, ec/ij), así como adición consonántica (j, y) (Véase el Cuadro № 16).

Cuadro № 14

Adición consonántica y mixta en el presente de subjuntivo

\begin{tabular}{|c|c|c|c|c|}
\hline \multirow{2}{*}{ Pron. } & “y” & "g” & “z” & "ig” \\
\hline Tú & Construyas & Salgas & Luzcas & Traigas \\
\hline Vos & Construyás & Salgás & Luzcás & Traigás \\
\hline Tú & Retribuyas & Tengas & Produzcas & Caigas \\
\hline Vos & Retribuyás & Tengás & Produzcás & Caigás \\
\hline Tú & Huyas & Vengas & Induzcas & Oigas \\
\hline Vos & Huyás & Vengás & induzcás & Oigás \\
\hline
\end{tabular}

Cuadro № 15

Otras irregularidades

\begin{tabular}{|c|l|c|c|c|}
\hline Pron. & IR & ESTAR & DAR & SER \\
\hline Tú & Vayas & Estés & Des & Seas \\
\hline Vos & Vayás & Estés & Des & Seás \\
\hline
\end{tabular}

Cuadro № 16

Conjugación irregular en pretérito imperfecto de subjuntivo

\begin{tabular}{|l|l|l|l|l|l|l|c|}
\hline Pron. & $\mathrm{O} / \mathrm{u}$ & $\mathrm{E} / \mathrm{i}$ & $\mathrm{C} / \mathrm{j}$ & $\mathrm{Ab} / \mathrm{up}$ & $\mathrm{Ec} / \mathrm{ij}$ & “j” & “y” \\
\hline Tú & Pudieras & Vinieras & Tradujeras & Supieras & Dijeras & Trajeras & Construyeras \\
\hline Vos & Pudieras & Vinieras & Tradujeras & Supieras & Dijeras & Trajeras & Construyeras \\
\hline Tú & & & Condujeras & Cupieras & Bendijeras & & Huyeras \\
\hdashline Vos & & & Condujeras & Cupieras & Bendijeras & & Huyeras \\
\hline
\end{tabular}


Hallamos aquí la misma terminación en el tuteo y el voseo; pero, además, las formas correspondientes a vos sufren los mismos cambios fonológicos que las de tú (debilitamiento, reemplazo mixto ab/up, ec/ij, etc.). Solamente por medio del uso del pronombre sujeto (vos, tú) determinará el hablante su preferencia por el voseo o tuteo. Las formas verbales correspondientes a vosotros también evidencian la presencia de los fenómenos descritos (pudierais, vinierais, condujerais, etc.); de lo cual inferimos que la pérdida de la -i de vosotros, por analogía, permitió homologar el vos y el tú.

\section{Pretérito perfecto y pluscuamperfecto}

Se aprecia en el perfecto (ver Cuadro № 11), el reemplazo consonántico $\mathbf{b}>\mathbf{y}$ en la raíz del auxiliar haber. Por analogía, las formas quedan parecidas; únicamente se distinguen por el valor acentual oxítono de la conjugación de vos. En el pluscuamperfecto, por analogía, las formas de vos posiblemente perdieron la -i heredada de la conjugación de vosotros, $y$, por lo tanto, quedaron homologadas las formas verbales del vos y del tú; nos referimos aquí a las formas en -ra por cuanto son las privilegiadas en la América hispanohablante, tanto en la escritura como en la oralidad. En el cuadro № 11, aparecen los ejemplos de la conjugación regular de este tiempo verbal.

\subsubsection{Modo imperativo}

Alcina Franch clasifica los verbos en tres grupos: de presente, de pretérito y romance (1975: 769). En el presente, se incluyen el de indicativo, de subjuntivo y de imperativo. De ahí que, si una forma verbal es irregular en el presente de indicativo, lo será también en presente de subjuntivo y de imperativo.

Imperativo positivo

Particularmente, tal como ejemplificamos en el Cuadro № 17, las formas del tuteo carecen de morfema específico para el imperativo positivo; se presenta pérdida de la $-\mathbf{s}$, característica de la segunda persona singular en los otros dos presentes. En cuanto al voseo, se nota que la -d sufre apócope. Según apunta Gili Gaya (1952:81), la pérdida de la -d final en el imperativo era frecuente entre los clásicos: andá, salí, etc., y lo es hoy en la América hispanohablante. Las formas de la tercera conjugación evidencian diferente vocal temática.

Imperativo negativo

El imperativo negativo se estructura con las formas negativas del subjuntivo presente. Las formas resultantes (véase Cuadro № 17) se distinguen únicamente por el acento agudo en el voseo (propio de la forma vosotros).

Cuadro № 17

Conjugación regular en presente de imperativo

\begin{tabular}{|c|c|c|c|}
\hline \multicolumn{4}{|c|}{ Imperativo positivo } \\
\hline Tú & Canta & Corre & Recibe \\
\hline Vos & Cantá & Corré & Recibí \\
\hline \multicolumn{4}{|c|}{ Imperativo negativo } \\
\hline Tú & No cantes & No corras & No recibas \\
\hline Vos & No cantés & No corrás & No recibás \\
\hline
\end{tabular}


Finalmente, en lo que respecta a las formas verbales irregulares, detectamos, en el presente positivo del tuteo, reemplazamiento vocálico y adición consonántica; según podemos observar en los ejemplos del Cuadro № 18 . Las formas del vos son todas agudas regulares, no debilitan ni diptongan la vocal radical y no se manifiesta inserción de consonante, aunque sí experimentan apócope de $-\mathbf{d}$, como se puntualizó con anterioridad.

En relación con las irregularidades verbales en el imperativo negativo, cabe observar que se seguirán las pautas ya marcadas para el presente de indicativo. Por ello, nos limitamos a reiterar algunos ejemplos, tal como se aprecia en el Cuadro №
18. Las formas del voseo también participan de estos cambios, si bien conservan su acento oxítono.

Por último, nos parece relevante destacar el hecho de que Alcina Franch (1975:774) incorpora los presentes agudos monosilábicos: poner, salir, hacer, dar, tener, venir, valer y decir (ver el Cuadro № 19). Dichas formas se distinguen claramente entre el voseo y el tuteo. No obstante, es fundamental destacar dos detalles: prácticamente todas las formas del imperativo con vos son regulares, y evidencian acento oxítono, con la excepción de las dos últimas formas, da y ve, las cuales son monosilábicas e idénticas a las correspondientes a tú; por consiguiente, se distinguirían echando mano al contexto pronominal.

Cuadro № 18

Irregularidades en el imperativo: Reemplazamiento vocálico y adición consonántica

\begin{tabular}{|l|l|l|l|l|l|l|}
\hline \multicolumn{7}{|c|}{ Formas positivas del presente de imperativo } \\
\hline Pron. & E/i & E/ie & I/ie & O/ue & U/ue & "y" \\
\hline Tú & Mide & Quiere & Requiere & Cuenta & Juega & Construye \\
\hline Vos & Medí & Queré & Requerí & Contá & Jugá & Construí \\
\hline Tú & Pide & & Inquiere & Muerde & & Retribuye \\
\hline Vos & Pedí & & Inquirí & Mordé & & Retribuí \\
\hline Tú & Sirve & & Adquiere & Duerme & & Huye \\
\hline Vos & Serví & & Adquirí & Dormí & & Huí \\
\hline
\end{tabular}

Formas negativas del presente de imperativo

\begin{tabular}{|c|l|l|l|l|l|l|l|}
\hline Pron. & E/i & E/ie & O/ue & C/g & Ec/ig & "g” & “ig” \\
\hline Tú & No midas & No sientas & No cuentes & No hagas & No digas & No salgas & No traigas \\
\hline Vos & No midás & No sintás & No contés & No hagás & No digás & No salgás & No traigás \\
\hline Tú & No pidas & No quieras & No muerdas & & & No vengas & No oigas \\
\hdashline Vos & No pidás & No querás & No mordás & & No vengás & No oigás \\
\hline
\end{tabular}

Cuadro № 19

Otras formas del imperativo

\begin{tabular}{|c|c|c|c|c|c|c|c|c|c|}
\hline Pron. & Poner & salir & hacer & Tener & venir & decir & Valer & Dar & Ver \\
\hline Tú & Pon & sal & haz & Ten & Ven & Di & Val & Da & Ve \\
\hline Vos & Poné & salí & hacé & Tené & vení & decí & Valé & da & Ve \\
\hline
\end{tabular}


En el Cuadro № 20, ofrecemos el paradigma completo de la conjugación de vos, y al lado la de tú, para contar con un modelo que nos permita establecer, de manera global, analogías y contrastes entre las formas.

Cuadro № 20

Paradigma verbal general del voseo en Costa Rica en comparación con el tuteo

\begin{tabular}{|c|c|c|c|}
\hline \multicolumn{2}{|c|}{ Tiempos simples } & \multicolumn{2}{|c|}{ Tiempos compuestos } \\
\hline Tuteo & Voseo & Tuteo & Voseo \\
\hline \multicolumn{4}{|c|}{ Indicativo } \\
\hline \multicolumn{2}{|l|}{ Presente } & \multicolumn{2}{|c|}{ Pretérito perfecto compuesto } \\
\hline Cantas & Cantás & Has cantado & Has cantado \\
\hline Corres & Corrés & Has corrido & Has corrido \\
\hline Recibes & Recibís & Has recibido & Has recibido \\
\hline \multicolumn{2}{|c|}{ Pretérito imperfecto } & \multicolumn{2}{|c|}{ Pretérito pluscuamperfecto } \\
\hline Cantabas & Cantabas & Habías cantado & Habías cantado \\
\hline Corrías & Corrías & Habías corrido & Habías corrido \\
\hline Recibías & Recibías & Habías recibido & Habías recibido \\
\hline \multicolumn{2}{|c|}{ Pretérito perfecto simple } & \multicolumn{2}{|l|}{ Pretérito anterior } \\
\hline Cantaste & Cantaste & Hubiste cantado & Hubiste cantado \\
\hline Corriste & Corriste & Hubiste corrido & Hubiste corrido \\
\hline Recibiste & Recibiste & Hubiste recibido & Hubiste recibido \\
\hline \multicolumn{2}{|c|}{ Condicional (potencial) } & \multicolumn{2}{|c|}{ Condicional (potencial) perfecto } \\
\hline Cantarías & Cantarías & Habrías cantado & Habrías cantado \\
\hline Correrías & Correrías & Habrías corrido & Habrías corrido \\
\hline Recibirías & Recibirías & Habrías recibido & Habrías recibido \\
\hline \multicolumn{2}{|l|}{ Futuro } & \multicolumn{2}{|l|}{ Futuro perfecto } \\
\hline Cantarás & Cantarás & Habrás cantado & Habrás cantado \\
\hline Correrás & Correrás & Habrás corrido & Habrás corrido \\
\hline Recibirás & Recibirás & Habrás recibido & Habrás recibido \\
\hline \multicolumn{4}{|c|}{ Subjuntivo } \\
\hline \multicolumn{2}{|l|}{ Presente } & \multicolumn{2}{|l|}{ Pretérito perfecto } \\
\hline Cantes & Cantés & Hayas cantado & Hayás cantado \\
\hline Corras & Corrás & Hayas corrido & Hayás corrido \\
\hline Recibas & Recibás & Hayas recibido & Hayás recibido \\
\hline \multicolumn{2}{|c|}{ Pretérito imperfecto } & \multicolumn{2}{|c|}{ Pretérito pluscuamperfecto } \\
\hline Cantaras & Cantaras & Hubieras cantado & Hubieras cantado \\
\hline Corrieras & Corrieras & Hubieras corrido & Hubieras corrido \\
\hline Recibieras & Recibieras & Hubieras recibido & Hubieras recibido \\
\hline \multicolumn{2}{|c|}{ Imperativo } & & \\
\hline \multicolumn{2}{|l|}{ Presente } & & \\
\hline Canta & Cantá & & \\
\hline Corre & Corré & & \\
\hline Recibe & Recibí & & \\
\hline
\end{tabular}




\subsection{En los pronombres}

\subsubsection{Personales}

El voseo actual requiere la presencia de te para expresar el complemento de verbo, no ha adoptado la forma oblicua os (equivalente a vos); mientras que para complemento término, complemento circunstancial, involucra la presencia de vos, forma que reemplaza $\boldsymbol{t} \boldsymbol{i}$, del tuteo; y con vos reemplaza a contigo. En el cuadro № 21 , puede apreciarse el paradigma completo de los pronombres personales en Costa Rica (Cfr. Víctor Sánchez, 1996:167). En los siguientes ejemplos hemos destacado los pronombres correspondientes a vos e indicado su función sintáctica.

"Yo TE quiero mucho"

Cd

"Rodolfo TE devolvió el libro A VOS ayer" Ci

$\mathbf{C i}$

¿A VOS TE gusta nadar en el mar?” Ci Ci

"Van a ir al cine CON VOS mañana" compl. Circ.

\subsubsection{Posesivos}

En cuanto a los posesivos, las formas vuestro/s, vuestra/s fueron sustituidas por tuyo/s, tuya/s y la forma apocopada $\boldsymbol{t} \boldsymbol{u} / \boldsymbol{s}$, provenientes del tuteo. En el cuadro № 21 , podemos apreciar las formas posesivas para los pronombres de segunda persona singular.

\subsection{En la ortografía}

En la presentación de los diferentes tiempos y modos del voseo, pudimos observar la particular presencia de la tilde (acentuación aguda) de estas formas en el grupo de presente (indicativo, subjuntivo, imperativo) así como en el pretérito perfecto de subjuntivo: corrés, corrás, hayás corrido. En los demás tiempos la acentuación y correspondiente uso de tilde corresponderá a las del tú: corriste, correrás, etc.

Nos queda pendiente referirnos a la acentuación de las formas verbales con pronombres enclíticos. En la última edición de la Ortografía de la lengua española (1999, 52-53), se estipula lo siguiente:

Cuadro № 21

Modelo pronominal de uso en Costa Rica

\begin{tabular}{|c|c|c|c|c|c|}
\hline \multicolumn{5}{|c|}{ Pronombres personales } & \multirow[t]{2}{*}{ Posesivos } \\
\hline & & Sujeto & Compl. verb. & Término & \\
\hline \multirow[t]{2}{*}{$\begin{array}{l}1^{\underline{a}} \\
\text { pers. }\end{array}$} & Singular & Yo & $\mathrm{Me}$ & Mí, (con)migo & $\begin{array}{l}\text { Mío, míos, } \\
\text { mía, mías }\end{array}$ \\
\hline & Plural & Nosotros/as & Nos & Nosotros/as & $\begin{array}{l}\text { Nuestro/s, } \\
\text { nuestra/s }\end{array}$ \\
\hline \multirow{4}{*}{$\begin{array}{l}2^{\underline{a}} \\
\text { pers. }\end{array}$} & Singular & Tú & Te & $\mathbf{T i}$ & \multirow{2}{*}{$\begin{array}{l}\text { Tuyo/s, tuya/s } \\
\text { Tu, tus }\end{array}$} \\
\hline & & Vos & $\mathbf{T e}$ & Vos & \\
\hline & & Usted & Lo /a, le, se & Usted & \multirow{4}{*}{$\begin{array}{l}\text { Suyo, suya, } \\
\text { suyos, suyas, } \\
\text { su, sus. }\end{array}$} \\
\hline & Plural & Ustedes & Los/las, les, se & Ustedes & \\
\hline \multirow{2}{*}{$\begin{array}{l}3^{\underline{a}} \\
\text { pers. }\end{array}$} & Singular & Él, ella, ello & Lo/la, le, se & El, ella, ello, sí, (con)sigo & \\
\hline & Plural & Ellos, ellas & Los/las, les, se & Ellos, ellas, sí, (con)sigo & \\
\hline
\end{tabular}


"Las formas verbales con pronombres enclíticos llevan tilde o no de acuerdo con las normas generales de acentuación. Ejemplos: cayose, pidiole, estate (todos casos de palabras llanas terminadas en vocal); mírame, dámelo, antójasele, habiéndosenos (casos de palabras esdrújulas y sobreesdrújulas). Las palabras de este tipo que ya no funcionan como verbos así como las compuestas por verbo más pronombre enclítico más complemento, siguen también, en cuanto al uso de la tilde, las normas generales. Ejemplos: acabose, sabelotodo, metomentodo".

Llevado lo anterior al empleo de las formas verbales de vos con pronombre enclítico, obtenemos, por ejemplo: cantámela, enviáselas, dejátelos (palabras esdrújulas); cantala, envialas, dejalos (palabras llanas u paroxítonas, por lo cual no se tildan).

\section{Conclusiones}

A través de la descripción de la conjugación del voseo en Costa Rica, observamos que, actualmente, no se traslapan paradigmas. Lo que se puede sentir como desorden y confusión en la conjugación entre tú y vos, es un fenómeno complejo, de largo cuño histórico; lo que se puede sentir como anarquía pronominal, el pasearse de un pronombre al otro, incluso en la misma frase, obedece a factores pragmático discursivos, más que sociales, los cuales aparecen bien ilustrados en los trabajos de Carlos Rojas y Yamilet Solano. Por ello, debemos hablar de alternancia pronominal, cuyas reglas están en estudio, y de las cuales los hablantes somos en general buenos usuarios intuitivos de la lengua.

En el español de Costa Rica (como en una diversidad de sitios de América), coexisten tres formas pronominales para dirigirse a la segunda persona singular: tú, vos y usted, cuya distribución geográfica y social está condicionada por fenómenos geográficos, de edad, sexo, nivel cultural, familiaridad, confianza y grado de amistad entre los interlocutores, costumbre, e, incluso, factores idiolectales, esto es, de preferencias o tendencias individuales de uso lingüístico.
Se evidencia, en lo relativo al tuteo, una valoración más positiva, y hasta más uso entre los hablantes jóvenes, los más expuestos a los medios colectivos (televisión, radio, programas de música, infantiles, anuncios comerciales). También, como ya se apuntó, el sistema escolar favorece el empleo de tú, a pesar de que ya está incorporado, en los programas oficiales, el estudio de las formas de tratamiento vos y usted. Otro motivo de la valoración positiva puede deberse al hecho de la afluencia, cada vez más alta, de extranjeros latinoamericanos tuteantes al territorio nacional (colombianos, venezolanos, peruanos, panameños, etc.), así como provenientes de otras lenguas.

Lamentablemente, se nota mucha valoración negativa hacia el empleo de vos. Por una parte, los hablantes manifiestan que es una forma 'corrupta', indicadora de educación deficiente, apartada de lo que dicta la gramática; pero, por otra, la valoran como espontánea, propia, de confianza. Tal actitud pueden haberla asumido al no haber aprendido a escribir empleando esta forma. Y, puede haber surgido, asimismo, en la inseguridad que se nota en los mismos centroamericanos, agravada por la ausencia de conciencia sobre la verdadera difusión de vos en Hispanoamérica (Lipsky, 1994: 160).

Los paradigmas del voseo, estudiados adecuadamente, pueden constituir valiosas herramientas no sólo para el campo lingüístico morfológico en la enseñanza secundaria, sino, también, para favorecer la eficacia comunicativa y el reconocimiento de nuestra identidad nacional. Finalmente, las variantes del voseo, analizadas convenientemente (y combinadas con otros rasgos que dividan toda Hispanoamérica con el mismo nivel de detalle), pueden servir para delimitar zonas dialectales, regionales y sociales y para reconstruir indirectamente la trayectoria que ha permitido la evolución de los dialectos del español de América. 


\section{Referencias bibliográficas}

Agüero, Arturo. El español de América y Costa Rica. San José: Atenea. 1962.

Alarcos Llorach, Emilio. Gramática de la lengua española. Madrid: ESPASACALPE. Colección Nebrija y Bello. 1995.

Alcina Franch, Juan y Blecua José Manuel. Gramática española. Barcelona: Editorial Ariel. 1975.

Alvar, M. y B. Potter. Morfosintaxis histórica del español. Madrid: Gredos. 1983.

Arroyo Soto, Víctor Manuel. El habla popular en la literatura costarricense. San José, Costa Rica: Publicaciones de la Universidad de Costa Rica. 1971.

Brown, Roger y Marguerite Ford. “Tratamiento personal en inglés norteamericano". En: Antología de estudios de etnolingüística y sociolingüística. $2^{\mathrm{a}}$ edición. México: UNAM. Pp. 314335. 1984.

Cano Aguilar, Rafael. El español a través de los tiempos. Madrid, España: Arco/Libro, S.A. 1988.

Silva Corvalan, Carmen. Sociolingüística y pragmática del español. USA: Georgetown University Press, Washington, D.C. 2001.

Cuervo, R.J. El castellano en América. Argentina: Librería y Editorial "El Ateneo". 1947.

Fontanella de Weinberg, María B. "La evolución de los pronombres de tratamiento en el español bonaerense". En: Thesaurus, XXV, Núm. 2. PP 1222. 1970.
"La construcción del paradigma pronominal del voseo". En: Thesaurus, XXXII, Núm. 2. Pp. 225239. 1977.

Gagini, Carlos. Elementos de gramática castellana. 7a. Edición. San José, Costa Rica: Librería Lehmann. 1929.

García de Diego, Vicente. Gramática histórica española. España: Gredos. 1951.

Garita, Flor. "Los procesos morfológicos que afectan los verbos irregulares en español”. En: Revista de Filología y Lingüística de la Universidad de Costa Rica. 2002.

Gili Gaya, Samuel. Nociones de gramática histórica española. España: Bibliograf, S.A. 1952.

González, Jézer. Curso fundamental de Gramática castellana. 1999.

Lapesa, R. Historia de la lengua española. España: Gredos. 1980.

Lathrop, Thomas A. Curso de gramática histórica española. Barcelona, España: Edit. Ariel S.A. 1992.

Lipski, John M. El español de América. España: Ediciones Cátedra. Traducción de Silvia Iglesias Recuero. 1996.

Marcos Marín, Francisco. Estudios sobre el pronombre. Madrid. 1978.

Mathews, P.H. Morfología: Introducción a la teoría de las estructuras de la palabra. Madrid, Paraninfo. 1980.

Menéndez Pidal, Ramón. Manual de gramática histórica española. Madrid: ESPASA-CALPE S.A. 1982. 
Moreno Fernández, Francisco. Principios de sociolingüística y sociología del lenguaje. Barcelona: Editorial Ariel S.A. 1998.

Plá Cáceres. La evolución del tratamiento 'vuestra merced'. En: RFE, X. 1923.

Quesada Pacheco, Miguel. El español colonial de Costa Rica. San José, Costa Rica: Editorial de la Universidad de Costa Rica. 1990.

. El español de América. Cartago, Costa Rica: Edit. Tecnológica de Costa Rica. 2000.

Real Acadamia Española. Esbozo de una nueva gramática de la lengua española. Madrid: Espasa-Calpe S.A. Décimo tercera reimpresión. 1991.

Real Acadamia Española. Ortografía de la lengua española. Madrid: EspasaCalpe S.A. 1999.

Resnick, Melvyn. Introducción a la historia de la lengua española. Washington D.C.: U. de Georgetown. 1981.

Rojas, Elena. "El voseo en el español de América". Hernández Alonso, César (Coordinador). Historia y presente del español de América. Valladolid: Junta de Castilla y León; 143-165. 1992.

ROJAS, Elena. El diálogo en el español de América. Estudio pragmalingüísticohistórico. Frankfurt: Vervuert. 1998.
Rona, José Pedro. "El problema de la división del español americano en zonas dialectales", Presente y futuro de la lengua española, t. I, 215-226, Madrid, OFINES. 1964.

Rona, José Pedro. Geografía y morfología del "voseo". Porto Alegre, Brasil: Pontificia Universidade Católica do Rio Grande do Sul. 1967.

Solano, Yamilet. "Formas de tratamiento diádico en los niños escolares de una comunidad de Costa Rica". En: Actas II Congreso Internacional sobre el español de América. México: 27-31 de enero. 1986.

Sánchez Corrales, Víctor Manuel, Marta Rojas Porras, Alí Víquez Jiménez. Español 8. Texto. San José, Costa Rica: Editorial de la Universidad de Costa Rica: PROMECE-Ministerio de Educación Pública. 1996.

Solé, Yolanda. "Correlaciones socio-culturales del uso de 'tú/vos' y 'usted' en Argentina, Perú y Puerto Rico”. En: Thesaurus. Tomo XXV, Núm. 2. PP 161-171. 1970.

Vargas Dengo, Carlos. "El uso de los pronombres 'vos' y 'usted' en Costa Rica”. En: Revista de Ciencias Sociales. 8, PP 7-30. 1974.

Weinerman, C. Sociolingüística de la forma pronominal. México: Edit. Trillas. 1976.

Lillyam Rojas Blanco Docente de la Escuela de Filología, Lingüística y Literatura de la Universidad de Costa Rica Docente de la Escuela de Literatura y Ciencias del Lenguaje de la Universidad Nacional 